\title{
Bond Strength of Fiber Posts to Composite Core: Effect of Surface Treatment With Er,Cr:YSGG Laser and Thermocycling
}

\author{
Sedighe Sadat Hashemikamangar ${ }^{1}$, Masoome Hasanitabatabaee ${ }^{1}$, Saman Kalantari ${ }^{1}$, \\ Mehrzad Gholampourdehaky ${ }^{2}$, Ladan Ranjbaromrani ${ }^{1}$, Hooman Ebrahimi ${ }^{3}$ \\ ${ }^{1}$ Operative Department, School of Dentistry, Tehran University of Medical Sciences, Tehran, Iran \\ ${ }^{2}$ Internal Medicine and Endocrinology, Medical Faculty, Aja University of Medical Sciences, Tehran, Iran \\ ${ }^{3}$ Laser Research Center, School of Dentistry, Tehran University Of Medical Sciences, International Campus, Tehran, Iran
}

\author{
*Correspondence to \\ Dr. Mehrzad Gholampourdehaky, \\ Assistant Professor, Internal Medicine \\ and Endocrinology, Medical Faculty, \\ Aja University of Medical Sciences, \\ Kargar St. Tehran, Iran. \\ Tel: +98 2188876011; \\ Fax: +982188876011; \\ Email: mehr_ghol@yahoo.com
}

Published online 26 December 2017

\begin{abstract}
Introduction: This study aimed to determine the bond strength of fiber post to composite core following surface treatment with Er,Cr:YSGG laser at different powers and sandblasting with and without thermocycling.

Methods: In this experimental study, 30 fiber posts (Glassix, Nordin, Switzerland) were randomly divided into 5 groups of sandblasting, no treatment and laser irradiation at 1, 1.5 and $2 \mathrm{~W}$ powers. Following composite filling and mounting, 1-mm thick sections were made for pushout bond strength testing. Half of the samples in each group were subjected to thermocycling $(n=15)$. Two-way analysis of variance (ANOVA) was used to analyze the bond strength values. Pairwise comparisons were made using Tukey test $(P<0.05)$.

Results: Effect of treatment method on push-out bond strength of fiber post to composite core was significant $(P=0.017)$, while thermocycling had no significant effect on bond strength $(P=0.964)$. Pairwise comparison of surface treatment methods revealed no significant difference in groups with and without thermocycling $(P>0.05)$, but Er,Cr:YSGG laser irradiation with $1 \mathrm{~W}$ power yielded significantly higher bond strength than the control group $(P=0.01)$.

Conclusion: Irradiation of Er,Cr:YSGG laser at $1 \mathrm{~W}$ power increased the bond strength of fiber post to composite core. Thermocycling slightly decreased the bond strength at the fiber postcore interface.
\end{abstract}

Keywords: Bond strength; Composite; Er,Cr:YSGG laser; Post.

\section{Introduction}

Endodontically treated teeth exhibit lower fracture strength than sound teeth due to considerable loss of tooth structure. Fiber posts are extensively used to provide retention for the core in permanent restoration of endodontically treated teeth. ${ }^{1}$

Prefabricated fiber posts have shown promising clinical results in terms of durability for use in endodontically treated teeth with moderate amount of remaining coronal tooth structure. Fiber posts have gained increasing popularity as an alternative to the traditional casting post and core restorations..$^{2-4}$ Prefabricated fiber posts adhesively bond to the root canal walls and provide retention for composite cores. Core build-up is done chairside and thus, eliminates the need for a laboratory fabrication step..$^{5-7}$ Fiber posts are often made of silanized glass or quartz fibers in an epoxy- or methacrylate-based resin matrix. No chemical reaction occurs between the organic matrix of fiber posts and methacrylate present in the core build-up material. ${ }^{8-10}$ Despite several advantages of fiber posts over the conventional posts, bond to intracanal dentin and core material has always been challenging for the former group. ${ }^{3,11,12}$

Some surface treatment methods including mechanical and chemical treatments have been proposed to enhance the bond of fiber posts to substrates, with controversial results. ${ }^{13-15}$ The chemical bond between fibers and resin materials is enhanced by the application of silane coupling agent. ${ }^{16-19}$ Application of silane increases the wettability of post surface; thus, an intimate contact can be obtained between the two materials. On the other hand, micromechanical retention can be provided by abrasion with air born particles measuring 25-30 $\mu$ in size, via increasing the surface area and microporosity. Resin penetrates into the microporosities and forms resin tags, which result in micromechanical interlocking

Please cite this article as follows: Hashemikamangar SS, Hasanitabatabaee M, Kalantari S, Gholampurdehaky M, Ranjbaromrani L, Ebrahimi $\mathrm{H}$. Bond strength of fiber posts to composite core: effect of surface treatment with Er,Cr:YSGG laser and thermocycling. J Lasers Med Sci. 2018;9(1):36-42. doi:10.15171/jlms.2018.09. 
and enhance the retention of the core material. ${ }^{19}$ Since no general consensus has been reached for an ideal clinical bonding process, attempts have been made to find alternative chemical and mechanical techniques for surface treatment of fiber posts to achieve higher bond strength. Surface treatment with Er,Cr:YSGG laser is among the suggested techniques.

The Er,Cr:YSGG laser is well absorbed by the water and minerals present in the formulation of hydroxyapatite crystals. Due to the absorption of Er,Cr:YSGG laser wavelength in water, it has several applications for the gingival tissue and oral mucosa. ${ }^{20}$ Due to its numerous advantages, this laser is used as a safe and effective surface treatment modality to enhance the bond strength. Moreover, laser irradiated surfaces may provide a strong bond to restorative materials thanks to numerous porosities and the absence of a smear layer. ${ }^{21}$

Application of laser in dentistry is becoming increasingly popular. Arslan et $\mathrm{al}^{22}$ reported that Er:YSGG laser irradiation at $4.5 \mathrm{~W}$ power was more effective for increasing the bond strength of fiber-glass posts to composite core, compared to sandblasting. However, Tuncdemir et al showed that Er:YAG laser irradiation at different powers had no significant effect on the bond of quartz fiber posts to resin cements. ${ }^{23}$ Moreover, Kurtulmus-Yilmaz et al assessed the effect of Er,Cr:YSGG laser irradiation on bond strength of fiber posts to resin cores, and reported that application of this laser at $1 \mathrm{~W}$ and $1.5 \mathrm{~W}$ power enhanced the bond at the post-core interface. ${ }^{24}$

To the best of the authors' knowledge, no previous study has evaluated the bond strength of fiber posts to composite core with/without thermocycling, and only one study was found on the effect of Er,Cr:YSGG laser irradiation on bond strength of fiber posts to composite cores, and it didn't evaluated the effect of thermocycling on the results. ${ }^{24}$

Duration and method of aging are among other factors affecting the success of composite restorations. Thus, artificial aging must be performed to simulate the clinical setting. Thermocycling and water storage are among the well-accepted artificial aging protocols for simulation of clinical oral environment. ${ }^{6}$ Thermocycling has been extensively used in studies on composite restorations, to simulate aging of composite bond. In this method, samples are subjected to severe thermal changes. High temperature degrades the physico-chemical properties of composite and compromises its bond. Thermal changes decrease the number of unreacted double bonds on the surface or within the composite, and negatively affect the composite bond strength. ${ }^{2}$

This study sought to assess the effect of Er,Cr:YSGG laser irradiation on push-out bond strength of fiber post to composite core, in comparison with sandblasting and no surface treatment.

\section{Methods}

Thirty glass fiber posts (Glassix \#3, Nordin, Switzerland) were used in this study to make all specimens. Based on the method of surface treatment, the posts were randomly divided into 5 groups. After cleaning the posts with alcohol, group 1 posts were subjected to $1 \mathrm{~W}$ Er,Cr:YSGG laser (Biolase, Waterlase, USA). Group 2 posts were subjected to $1.5 \mathrm{~W}$ Er,Cr:YSGG laser. Group 3 posts were subjected to $2 \mathrm{~W}$ Er,Cr:YSGG laser. Group 4 posts were sandblasted and group 5 posts had no treatment. For surface treatment with laser, laser was set on $\mathrm{H}$ mode and each fiber post was lased for 2 cycles with a swiping motion; each cycle of laser treatment took 40 seconds. Each laser power was used with $20 \mathrm{~Hz}$ frequency, $60 \%$ water, $40 \%$ air and $\Delta \mathrm{t}$ of $60 \mu \mathrm{s}$. Fiber posts in the sandblasting group were sandblasted with $50 \mu \mathrm{Al}_{2} \mathrm{O}_{3}$ particles at 2.8 bar pressure for 5 seconds from $10 \mathrm{~mm}$ distance.

After cleaning the posts by immersing in ultrasonic bath containing water for 4 minutes, silane (PULPDENT, Watertown, USA) was applied on all fiber posts and gently air-dried after 1 minute. Bonding agent (Single Bond, 3M ESPE, St. Paul, MN, USA) was then applied on the entire surface of fiber posts and each surface was cured for 20 seconds using a light curing unit with light intensity of $600 \mathrm{~mW} / \mathrm{cm}^{2}$ (Woodpecker, Shanghai, China). The apical third of each post was placed in a surveyor and adjusted perpendicular to a glass slab. A cylindrical plexiglass mold measuring $8 \mathrm{~mm}$ in diameter and $2 \mathrm{~mm}$ in thickness was placed over the post surrounding its non-tapered zone in such a way that the post was approximately positioned at the center of the mold. After post placement, composite (P60, 3M ESPE, St. Paul, MN, USA) was applied to the mold in $2 \mathrm{~mm}$ increments and was cured for 20 seconds using the same light curing unit. Then, another mold was placed above the previous one and filled similarly. The procedure continued until the non-tapered zone of each post was completely filled. Next, the remaining tapered part of each post was cut. After that, all composite-post blocks were immersed in distilled water at $37^{\circ} \mathrm{C}$ for 24 hours. Finally, the composite_post blocks were mounted in epoxy resin and sectioned perpendicular to apicalcoronal direction to $1-\mathrm{mm}$ thickness using a Mecatome (Presi, France). By doing so, 5 samples were obtained of each composite-post blocks approximately, and a total of 30 samples for each groups. Half of the samples in each group were thermocycled $\left(10000\right.$ cycles, $5^{\circ} \mathrm{C}-55^{\circ} \mathrm{C}, 20$ seconds of dwell time and 10 seconds of transfer time), while the other half were not $(n=15)$. Samples' thickness was measured by a digital caliper and all samples were subjected to push-out bond strength tests by the universal testing machine (Zwick Roell, Ulm, Germany). The bond strength values were recorded in megapascals ( $\mathrm{MPa})$.

$P=\frac{N}{A}(A=2 r \times \pi \times h)$

The samples were loaded by a cylindrical plunger with 
$0.8 \mathrm{~mm}$ diameter at the center of posts without contact with the surrounding core surfaces. Load was applied in an apical-coronal direction at a crosshead speed of 1 $\mathrm{mm} / \mathrm{min}$ and continued until the post displacement. Maximum load at post displacement was measured in Newton and calculated and reported in MPa. The samples were then evaluated under a stereomicroscope (Nikon, Tokyo, Japan) to determine the mode of failure at $\times 40$ magnification.

Five fiber posts (one of each group) were prepared and after the gold coating under sputter coater (SBC12, KYKY, China) for 30 minutes, they were evaluated under a scanning electron microscope (SEM) at $\times 500$ magnification (EM3200, KYKY, China) and micrographs were captured for assessment of surface morphology.

The data were analyzed using SPSS version 21.0. Descriptive statistics were applied and the mean and standard deviation (SD) of push-out bond strength of fiber posts to composite core were reported for the five groups. Two-way analysis of variance

( ANOVA) was applied to assess the effect of surface treatment method and conduction of thermocycling on the results. Tukey test was used for pairwise comparisons of the groups. Type one error was considered as 0.05 .

\section{Results}

The mean and SD of push-out bond strength of fiber posts to composite core, following sandblasting with and without thermocycling, were $15.76 \pm 4.22 \mathrm{MPa}$ and $16.56 \pm 3.46 \mathrm{MPa}$, respectively. In the control group with and without thermocycling, these values were $12.59 \pm 2.95$ and $14.68 \pm 2.16 \mathrm{MPa}$, respectively. These values in the $1 \mathrm{~W}, 1.5 \mathrm{~W}$ and $2 \mathrm{~W}$ laser groups with and without thermocycling were $17.02 \pm 7.81 \mathrm{MPa}$ and $18.3 \pm 4.02 \mathrm{MPa}, 14.19 \pm 4.11 \mathrm{MPa}$ and $15.18 \pm 6.28 \mathrm{MPa}$ and $14.83 \pm 4.99 \mathrm{MPa}$ and $15.11 \pm 5.19 \mathrm{MPa}$, respectively (Table 1 and Figure 1).

Based on the results of two-way ANOVA, the effect of treatment method on push-out bond strength of fiber post to composite core was significant $(P=0.017)$ but thermocycling had no significant effect on bond strength $(P=0.17)$. The interaction effect of thermocycling and treatment method on bond strength was not significant

Table 1. Descriptive Statistics for the Push-out Bond Strength of Fiber Posts to Composite Core in the 5 Groups With/Without Thermocycling and Pairwise Comparison

\begin{tabular}{lcc}
\hline \multirow{2}{*}{ Group } & \multicolumn{2}{c}{ Bond Strength } \\
\cline { 2 - 3 } & Termocycling & No Termocycling \\
\hline Control & $12.59(2.95)^{\mathrm{a}}$ & $14.68(2.16)^{\mathrm{a}}$ \\
Sandblasting & $15.76(4.22)^{\mathrm{a}, \mathrm{b}}$ & $16.56(3.46)^{\mathrm{a}, \mathrm{b}}$ \\
Laser 1 W & $17.02(7.81)^{\mathrm{b}}$ & $18.30(4.02)^{\mathrm{b}}$ \\
Laser 1.5 W & $14.19(4.11)^{\mathrm{a}, \mathrm{b}}$ & $15.18(6.28)^{\mathrm{a}, \mathrm{b}}$ \\
Laser 2 W & $14.83(4.99)^{\mathrm{a}, \mathrm{b}}$ & $15.11(5.19)^{\mathrm{a}, \mathrm{b}}$ \\
\hline
\end{tabular}

Different letter shows the statistically significant difference. neither $(P=0.96)$.

Considering the significant effect of different surface treatment methods on push-out bond strength of fiber posts to composite core, Tukey test was applied for pairwise comparisons of bond strength values. Based on Table 1, a significant difference was only found between the control (no surface treatment) and $1 \mathrm{~W}$ laser groups $(P=0.01)$, and no other significant difference was noted between different surface treatment groups in terms of bond strength of fiber post to composite core.

The frequency of failure modes is shown in Table 2. Overall, the frequency percentage of adhesive, cohesive within the core, cohesive within the post and mixed failures were found to be $87 \%, 5.33 \%, 2.67 \%$ and $5.33 \%$, respectively.

The micrographs of SEM analysis can be seen in Figure 2.

\section{Discussion}

Based on the results of this study, surface treatment method of fiber posts had a significant effect on their bond strength to composite core, but thermocycling had no such effect.

It has been documented that chemical composition (size, type, distribution and percentage of fibers) and surface topography of posts affect the post-resin core bond strength. ${ }^{23,25,26}$ In the current study, only one type of glass post (Glassix) was used to assess the effect of different surface treatment protocols on bond strength. Fiber posts have uniform, smooth surfaces limiting mechanical interlocking between the post surface and resin core. ${ }^{1}$ To obtain a bond between the methacrylate-based resin of the core material and resin matrix of the fiber post, fiber posts must undergo mechanical or chemical surface treatment to react with silane molecules. ${ }^{27}$ In the current study, samples were prepared with $1 \mathrm{~W}, 1.5 \mathrm{~W}$ and $2 \mathrm{~W}$ Er,Cr:YSGG laser, or by sandblasting plus silanization. On the other hand, thermocycling was performed for half the samples in each group, because in the clinical setting, bond

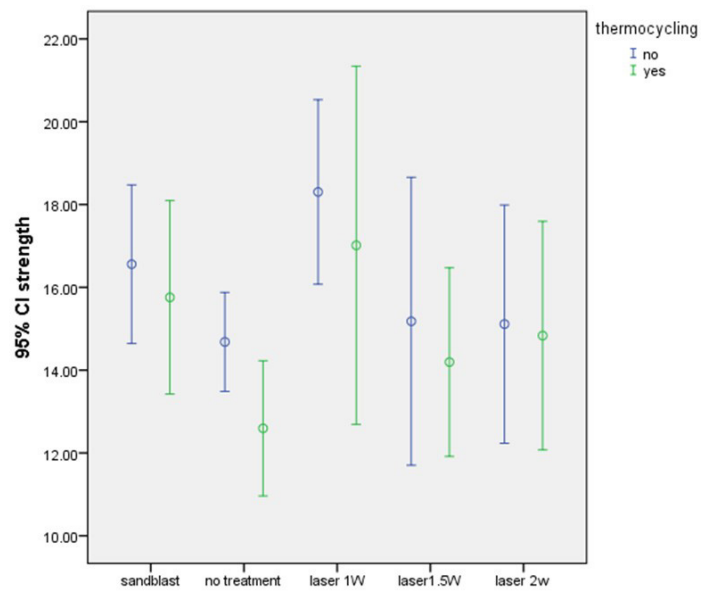

Figure 1. Push-out Bond Strength of Fiber Posts to Composite Core in the 5 Groups With and Without Thermocycling 
Table 2. The Frequency of Modes of Failure in the 5 Surface Treatment Groups With and Without Thermocycling

\begin{tabular}{|c|c|c|c|c|c|}
\hline \multirow[b]{2}{*}{ Group } & \multirow[b]{2}{*}{ Thermocycling } & \multicolumn{4}{|c|}{$\begin{array}{l}\text { Failure Pattern } \\
\end{array}$} \\
\hline & & $\begin{array}{l}\text { Adhesive } \\
\text { No. (\%) }\end{array}$ & $\begin{array}{c}\text { Cohesive Within the Core } \\
\text { No. }(\%)\end{array}$ & $\begin{array}{c}\text { Cohesive Within the Post } \\
\text { No. }(\%)\end{array}$ & $\begin{array}{c}\text { Mixed } \\
\text { No. }(\%)\end{array}$ \\
\hline \multirow{2}{*}{ Control } & Yes & $13(86.87)$ & $1(6.67)$ & $0(0)$ & $1(6.67)$ \\
\hline & No & $12(80)$ & $2(13.33)$ & $0(0)$ & $1(6.67)$ \\
\hline \multirow{2}{*}{ Sandblasting } & Yes & $15(100)$ & $0(0)$ & $0(0)$ & $0(0)$ \\
\hline & No & $13(86.87)$ & $1(6.67)$ & $1(6.67)$ & $0(0)$ \\
\hline \multirow{2}{*}{ Laser $1 \mathrm{~W}$} & Yes & $15(100)$ & $1(6.67)$ & $0(0)$ & $0(0)$ \\
\hline & No & $12(80)$ & $0(0)$ & $1(6.67)$ & $2(13.33)$ \\
\hline \multirow{2}{*}{ Laser $1.5 \mathrm{~W}$} & Yes & $13(86.67)$ & $0(0)$ & $0(0)$ & $2(13.33)$ \\
\hline & No & $12(80)$ & $1(6.67)$ & $2(13.33)$ & $0(0)$ \\
\hline \multirow{2}{*}{ Laser $2 \mathrm{~W}$} & Yes & $12(80)$ & $1(6.67)$ & $0(0)$ & $2(13.33)$ \\
\hline & No & $14(93.33)$ & $1(6.67$ & $0(0)$ & $0(0)$ \\
\hline
\end{tabular}
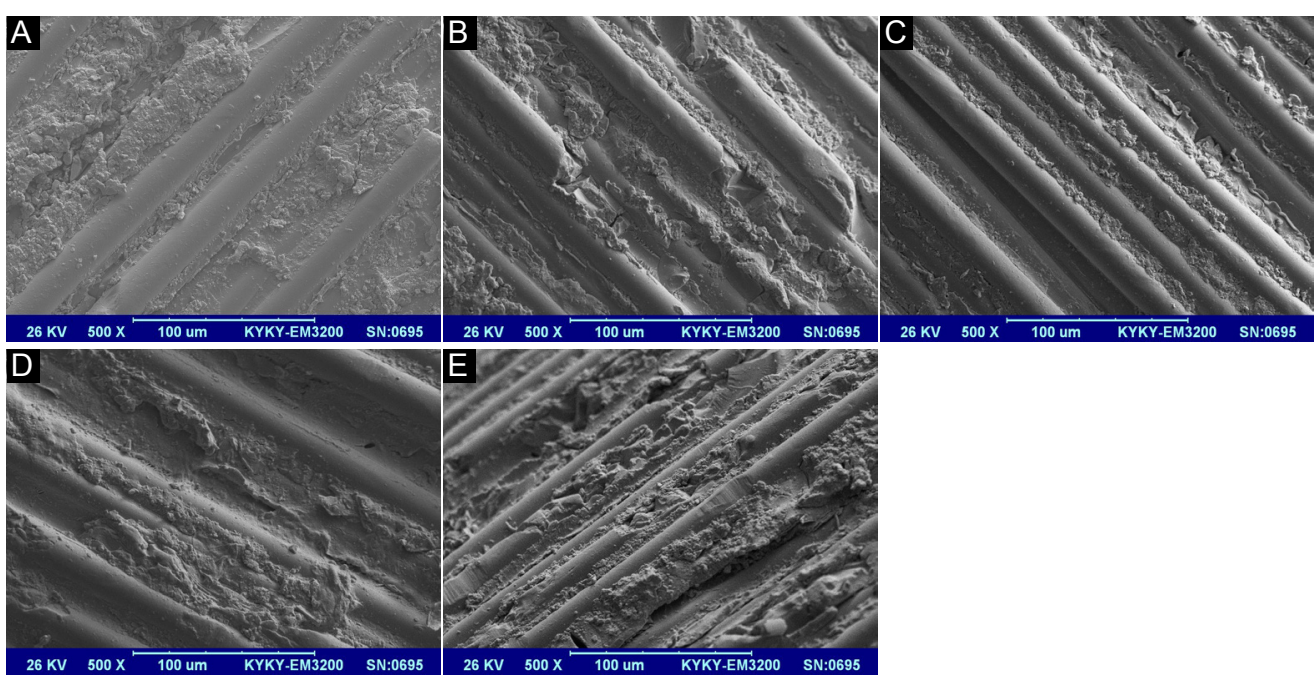

Figure 2. The SEM Micrographs ( $\times 500)$ of Fiber Post Surfaces in the 5 Groups of no Treatment (A), Sandblasting (B), $1 \mathrm{~W}$ Laser (C), $1.5 \mathrm{~W}$ Laser (D) and $2 \mathrm{~W}$ Laser (E).

strength is affected by chemical, thermal and mechanical factors in the oral cavity; however, in the current study, thermocycling had no significant effect on push-out bond strength of fiber posts to resin core. But, the bond strength values in the thermocycled samples were slightly lower than the values in the non-thermocycled samples. In the current study, the mean and SD of push-out bond strength of fiber posts to composite core following sandblasting with and without thermocycling was found to be $15.76 \pm 4.22 \mathrm{MPa}$ and $16.56 \pm 3.46 \mathrm{MPa}$, respectively; the difference in bond strength between this method and other protocols was not significant.

It has been reported that sandblasting with $\mathrm{Al}_{2} \mathrm{O}_{3}$ particles may cause cracks in the post. ${ }^{28}$ Previous studies recommended mild sandblasting to prevent crack formation and minimize dimensional changes of fiber posts. ${ }^{29,30}$ Thus, in the current study, sandblasting was performed with $5 \mu \mathrm{Al}_{2} \mathrm{O}_{3}$ particles at 2.8 bar pressure for 5 seconds from $10 \mathrm{~mm}$ distance. ${ }^{31}$ The SEM micrographs in the sandblasted group revealed irregular dugout areas of resin matrix all over the fiber posts.

The results of the current study showed that the mean and SD of push-out bond strength of fiber posts to composite core following $1 \mathrm{~W}, 1.5 \mathrm{~W}$ and $2 \mathrm{~W}$ laser irradiation with and without thermocycling were $17.02 \pm 7.81 \mathrm{MPa}$ and $18.3 \pm 4.02, \mathrm{MPa}, 14.19 \pm 4.11 \mathrm{MPa}$ and $15.18 \pm 6.28 \mathrm{MPa}$ and $14.83 \pm 4.99 \mathrm{MPa}$ and $15.11 \pm 5.19 \mathrm{MPa}$, respectively. No significant difference was noted in the bond strength of 1.5 and $2 \mathrm{~W}$ laser groups and that of other groups; however, the bond strength of $1 \mathrm{~W}$ Er,Cr:YSGG laser group was significantly higher than that of no treatment group.

Laser irradiation is a safe and simple surface treatment method for some dental materials. ${ }^{32,33}$ Some recent studies evaluated the effects of different powers of Er:YAG laser on bond strength of fiber posts. ${ }^{22,23,33,34}$ Sipahi et al demonstrated that Er:YAG laser irradiation with $150 \mathrm{~mJ}$ power and $10 \mathrm{~Hz}$ frequency increased the bond strength 
of glass fiber posts ${ }^{34}$ but Tuncdemir et al reported that Er:YAG laser with the afore-mentioned parameters had no significant effect on push-out bond strength of quartz fiber posts. ${ }^{23}$ On the other hand, Arslan et al used Er:YAG laser with 150,300 and $450 \mathrm{~mJ}$ powers and $10 \mathrm{~Hz}$ frequency for treatment of glass fiber posts and showed that Er:YAG laser irradiation at $450 \mathrm{~mJ}$ power increased the push-out ${ }^{22}$ and pull-out ${ }^{33}$ bond strength of fiber-post to resin core. Akin et al evaluated the bond strength of quartz fiber posts after different surface treatment methods and reported the highest bond strength in the sandblasted followed by the Er:YAG laser irradiated groups; these two methods significantly increased the bond strength of quartz fiber posts to resin cement. ${ }^{35}$ Moreover, Kriznar et al evaluated the micro-push-out bond strength of Multicore Flow resin material to 2 types of fiber posts following Er:YAG laser irradiation, and showed that Er:YAG laser irradiation negatively affected the bond strength of resin material to fiber posts. ${ }^{16}$ Controversial results of different studies may be attributed to factors such as type of fiber post and differences in laser parameters.

On the other hand, Er,Cr:YSGG laser used in the current study may have effects similar to those of Er:YAG laser since its wavelength $(2.78 \mathrm{~nm})$ is close to that of Er:YAG laser $(2.94 \mathrm{~nm}){ }^{36}$ The efficacy of Er,Cr:YSGG laser for surface treatment of dentin, ${ }^{37,38}$ ceramics ${ }^{38}$ and composite resin ${ }^{39}$ has been previously evaluated. Kurtulmus-Yilmaz et al evaluated the effect of Er,Cr:YSGG laser on micropush-out bond strength of fiber post to resin core, and showed that laser irradiation in $1 \mathrm{~W}$ and $1.5 \mathrm{~W}$ powers enhanced the bond strength, but $2 \mathrm{~W}$ laser irradiation had no such effect. ${ }^{24}$ Similarly, irradiation of $1 \mathrm{~W}$ laser in the current study improved the bond strength.

High (2 W) power laser may destruct fibers and compromise the homogeneity and integrity of posts, which can eventually decrease the ability of posts to bond to silane and resin core material. Higher laser powers can cause severe physical damage to fiber posts, and the generated heat in this process may adversely affect the chemical composition of composite and compromise the quality of bond of fiber posts to composite core. ${ }^{24}$ In the current study, SEM micrographs of 1.5 and $2 \mathrm{~W}$ laser treated groups revealed areas of resin matrix and fiber dugout; however, in $1 \mathrm{~W}$ laser treated group, only resin matrix had been dugout in some areas between fibers, and the fibers remained intact.

Er,Cr:YSGG laser wavelength is in the infrared spectrum. Laser beams are aimed at the target organs via a fiber-optic system. In this laser, photons are reinforced in a medium of heterogeneous crystals. The laser emits photons at 2780 $\mathrm{nm}$ wavelength in $140 \mu$ s pulse and $10-50 \mathrm{~Hz}$ frequency. Laser irradiation of soft and hard tissues is a complex topic due to complicated interactions of laser energy, water and tissues. ${ }^{40}$ When tissues react to laser energy, the resultant outcome will be determined by the wavelength of laser, optical characteristics of tissue, duration of irradiation, laser energy and rate of laser absorption by the tissue. Laser absorption plays a major role in conversion of laser light energy to heat, sound or chemical energy between atoms and molecules in the target organ. Thus, the required laser energy to achieve a desired outcome would be variable depending on the type of target tissue. ${ }^{40}$

Chemical affinity between the two components is also an important determinant of bond strength. ${ }^{41}$ The surface of fiber posts is so polymerized that they are no longer capable of reacting or bonding to free radicals. ${ }^{42}$ The bond strength of composite resins to fiber posts is often limited due to chemical heterogeneity between methacrylatebased resins and epoxy resins in the post. ${ }^{43}$ Also, the composition of resin polymer matrix in the post can affect the ability of adhesive to penetrate between the fibers and provide adequate micromechanical retention. ${ }^{10}$ The main component in the composition of resin can also affect the bond to fiber posts. ${ }^{44}$ On the other hand, it seems that the surface roughness created by the manufacturer and the modifications made in the epoxy resin matrix of the post for bond to Bis-GMA also decrease the efficacy of surface treatments to enhance the bond strength. ${ }^{11}$

Based on the results of the current study, 10000 cycles of thermocycling (equals to one year of clinical service), ${ }^{45}$ had no significant effect on bond strength of fiber posts to composite core; although it slightly (but not significantly) decreased the bond strength. Considering the necessity of simulation of clinical setting in in-vitro studies, we performed thermocycling as a standard method of artificial aging. ${ }^{6}$

In the current study, push-out loads were applied to samples to prevent creation of heterogeneous stresses in them. Some researchers believe that push-out bond strength testing is more reliable than the microtensile test for measurement of bond strength of fiber posts to radicular dentin ${ }^{46}$ because the push-out test highly resembles an actual shear test and provides a more reliable and accurate estimation of bond strength compared to the conventional shear test. ${ }^{47}$ The only shortcoming of the push-out strength test is unequal stress distribution in thick samples; this problem can be eliminated by slicing the samples to obtain thin sections. ${ }^{46}$ Goracci et al compared the efficacy of microtensile and push-out tests for accurate assessment of bond strength of fiber posts cemented in the post space, and showed that pushout test was more accurate than the microtensile test for measurement of bond strength of cemented fiber posts. ${ }^{46}$ In the push-out technique, all prepared samples can be used and the dispersion of results would be lower; whereas in microtensile test, numerous primary fractures occur in the samples and the results would have high dispersion. ${ }^{46}$ In the current study, $87 \%$ of the failures were of adhesive type and occurred at the fiber post-resin core interface in different surface treatment groups. 
In the current study, 10000 thermal cycles (corresponding to approximately one year of clinical service) had no significant effect on bond strength; the effect of longer duration of aging on bond strength must be evaluated in future studies.

In vitro studies cannot completely simulate the oral clinical conditions. In the oral cavity, restored teeth are exposed to numerous variables; they are constantly exposed to moisture, thermal alterations and variations in $\mathrm{pH}$ due to a variety of diets. Moreover, they are exposed to bacteria and different enzymes and are subjected to masticatory forces. All these factors have undeniable effects on the bond strength of fiber posts to composite core, and may compromise the clinical service of posts. Thus, the effect of these parameters on bond strength of posts to composite core can be an interesting topic for future studies.

Our in vitro assessment of surface treatment effect of fiber posts with Er,Cr:YSGG laser on their bond to composite core with and without thermocycling by all its limitations, revealed that irradiation of Er,Cr:YSGG laser with $1 \mathrm{~W}$ power effectively enhanced the bond strength of fiber posts to composite core, and thermocycling slightly (but not significantly) decreased the bond strength at the postcore interface.

\section{Conflict of Interests}

The authors declare no conflict of interest.

\section{Ethical Considerations}

Since this research is an experimental study, there is no ethical consideration.

\section{References}

1. Balbosh A, Kern M. Effect of surface treatment on retention of glass-fiber endodontic posts. J Prosthet Dent. 2006;95(3):218-223. doi:10.1016/j.prosdent.2006.01.006.

2. Fredriksson M, Astback J, Pamenius M, Arvidson K. A retrospective study of 236 patients with teeth restored by carbon fiber-reinforced epoxy resin posts. J Prosthet Dent. 1998;80(2):151-157.

3. Monticelli F, Grandini S, Goracci C, Ferrari M. Clinical behavior of translucent-fiber posts: a 2-year prospective study. Int J Prosthodont. 2003;16(6):593-596.

4. Malferrari S, Monaco C, Scotti R. Clinical evaluation of teeth restored with quartz fiber-reinforced epoxy resin posts. Int J Prosthodont. 2003;16(1):39-44.

5. Robbins JW. Guidelines for the restoration of endodontically treated teeth. J Am Dent Assoc. 1990;120(5):558.

6. Gutmann JL. The dentin-root complex: anatomic and biologic considerations in restoring endodontically treated teeth. J Prosthet Dent. 1992;67(4):458-467.

7. Schwartz RS, Robbins JW. Post placement and restoration of endodontically treated teeth: a literature review. J Endod. 2004;30(5):289-301. doi:10.1097/00004770-20040500000001.

8. Kallio TT, Lastumaki TM, Vallittu PK. Bonding of restorative and veneering composite resin to some polymeric composites. Dent Mater. 2001;17(1):80-86.

9. Lastumaki TM, Lassila LV, Vallittu PK. The semiinterpenetrating polymer network matrix of fiberreinforced composite and its effect on the surface adhesive properties. J Mater Sci Mater Med. 2003;14(9):803-809.

10. Mannocci F, Sherriff M, Watson TF, Vallittu PK. Penetration of bonding resins into fibre-reinforced composite posts: a confocal microscopic study. Int Endod J. 2005;38(1):46-51. doi:10.1111/j.1365-2591.2004.00900.x.

11. Bouillaguet S, Troesch S, Wataha JC, Krejci I, Meyer JM, Pashley DH. Microtensile bond strength between adhesive cements and root canal dentin. Dent Mater. 2003;19(3):199205.

12. Ferrari M, Cagidiaco MC, Grandini S, De Sanctis M, Goracci C. Post placement affects survival of endodontically treated premolars. J Dent Res. 2007;86(8):729-734. doi:10.1 $177 / 154405910708600808$.

13. Vano M, Goracci C, Monticelli F, et al. The adhesion between fibre posts and composite resin cores: the evaluation of microtensile bond strength following various surface chemical treatments to posts. Int Endod J. 2006;39(1):31-39. doi:10.1111/j.1365-2591.2005.01044.x.

14. Faria MI, Gomes E, Messias DC, Silva Filho JM, Souza Filho CB, Paulino SM. Tensile strength of glass fiber posts submitted to different surface treatments. Braz Dent J. 2013;24(6):626-629. doi:10.1590/0103-6440201302365.

15. Soares CJ, Santana FR, Pereira JC, Araujo TS, Menezes MS. Influence of airborne-particle abrasion on mechanical properties and bond strength of carbon/epoxy and glass/ bis-GMA fiber-reinforced resin posts. $J$ Prosthet Dent. 2008;99(6):444-454. doi:10.1016/s0022-3913(08)60106-7.

16. Kriznar I, Jevnikar P, Fidler A. Effect of Er:YAG laser pretreatment on bond strength of a composite core buildup material to fiber posts. Lasers Med Sci. 2015;30(2):733740. doi:10.1007/s10103-013-1412-4.

17. Aksornmuang J, Foxton RM, Nakajima M, Tagami J. Microtensile bond strength of a dual-cure resin core material to glass and quartz fibre posts. J Dent. 2004;32(6):443-450. doi:10.1016/j.jdent.2004.03.001.

18. Matinlinna JP, Lassila LV, Ozcan M, Yli-Urpo A, Vallittu PK. An introduction to silanes and their clinical applications in dentistry. Int J Prosthodont. 2004;17(2):155-164.

19. Goracci C, Raffaelli O, Monticelli F, Balleri B, Bertelli E, Ferrari M. The adhesion between prefabricated FRC posts and composite resin cores: microtensile bond strength with and without post-silanization. Dent Mater. 2005;21(5):437444. doi:10.1016/j.dental.2004.07.012.

20. Harashima T, Kinoshita JI, Kimura Y, et al. Morphological comparative study on ablation of dental hard tissues at cavity preparation by Er: YAG and Er, Cr: YSGG lasers. Photomedicine and Laser Therapy. 2005;23(1):52-5.

21. Hossain M, Nakamura Y, Yamada Y, Murakami Y, Matsumoto K. Microleakage of composite resin restoration in cavities prepared by Er,Cr:YSGG laser irradiation and etched bur cavities in primary teeth. J Clin Pediatr Dent. 2002;26(3):263-268.

22. Arslan H, Barutcigil C, Yilmaz CB, Ceyhanli KT, Topcuoglu HS. Push-out bond strength between composite core buildup and fiber-reinforced posts after different surface treatments. Photomed Laser Surg. 2013;31(7):328-333. doi:10.1089/pho.2013.3478. 
23. Tuncdemir AR, Yildirim C, Guller F, Ozcan E, Usumez A. The effect of post surface treatments on the bond strength of fiber posts to root surfaces. Lasers Med Sci. 2013;28(1):13-18. doi:10.1007/s10103-012-1053-z.

24. Kurtulmus-Yilmaz S, Cengiz E, Ozan O, Ramoglu S, Yilmaz HG. The effect of Er,Cr:YSGG laser application on the micropush-out bond strength of fiber posts to resin core material. Photomed Laser Surg. 2014;32(10):574-581. doi:10.1089/pho.2014.3780.

25. Cekic-Nagas I, Sukuroglu E, Canay S. Does the surface treatment affect the bond strength of various fibre-post systems to resin-core materials? J Dent. 2011;39(2):171179. doi:10.1016/j.jdent.2010.11.008.

26. Elsaka SE. Influence of chemical surface treatments on adhesion of fiber posts to composite resin core materials. Dent Mater. 2013;29(5):550-558. doi:10.1016/j. dental.2013.03.004.

27. Kulunk S, Kulunk T, Yenisey M. Effects of different surface pre-treatments on the bond strength of adhesive resin cement to quartz fiber post. Acta Odontol Scand. 2012;70(6):547-554. doi:10.3109/00016357.2011.629623.

28. Valandro LF, Yoshiga S, de Melo RM, et al. Microtensile bond strength between a quartz fiber post and a resin cement: effect of post surface conditioning. $J$ Adhes Dent. 2006;8(2):105-111.

29. D’Arcangelo C, D’Amario M, Vadini M, De Angelis F, Caputi S. Influence of surface treatments on the flexural properties of fiber posts. J Endod. 2007;33(7):864-867. doi:10.1016/j.joen.2007.03.004.

30. Kern M, Thompson VP. Sandblasting and silica coating of a glass-infiltrated alumina ceramic: volume loss, morphology, and changes in the surface composition. J Prosthet Dent. 1994;71(5):453-461.

31. Yenisey M, Kulunk S. Effects of chemical surface treatments of quartz and glass fiber posts on the retention of a composite resin. J Prosthet Dent. 2008;99(1):38-45. doi:10.1016/s0022-3913(08)60007-4.

32. Spohr AM, Borges GA, Junior LH, Mota EG, Oshima HM. Surface modification of In-Ceram Zirconia ceramic by Nd:YAG laser, Rocatec system, or aluminum oxide sandblasting and its bond strength to a resin cement. Photomed Laser Surg. 2008;26(3):203-208. doi:10.1089/ pho.2007.2130.

33. Arslan H, Kurklu D, Ayranci LB, et al. Effects of post surface treatments including Er:YAG laser with different parameters on the pull-out bond strength of the fiber posts. Lasers Med Sci. 2014;29(5):1569-1574. doi:10.1007/s10103013-1485-0.

34. Sipahi C, Piskin B, Akin GE, Bektas OO, Akin H. Adhesion between glass fiber posts and resin cement: evaluation of bond strength after various pre-treatments. Acta Odontol Scand. 2014;72(7):509-515. doi:10.3109/00016357.2013.87 5586.

35. Akin GE, Akin H, Sipahi C, Piskin B, Kirmali O. Evaluation of surface roughness and bond strength of quartz fiber posts after various pre-treatments. Acta Odontol Scand. 2014;72(8):1010-1016. doi:10.3109/00016357.2014.93 9710.

36. Hossain M, Nakamura Y, Yamada Y, Kimura Y, Matsumoto N, Matsumoto K. Effects of Er,Cr:YSGG laser irradiation in human enamel and dentin: ablation and morphological studies. J Clin Laser Med Surg. 1999;17(4):155-159. doi:10.1089/clm.1999.17.155.

37. Garbui BU, de Azevedo CS, Zezell DM, Aranha AC, Matos AB. Er,Cr:YSGG laser dentine conditioning improves adhesion of a glass ionomer cement. Photomed Laser Surg. 2013;31(9):453-460. doi:10.1089/pho.2013.3546.

38. Kursoglu P, Motro PF, Yurdaguven H. Shear bond strength of resin cement to an acid etched and a laser irradiated ceramic surface. J Adv Prosthodont. 2013;5(2):98-103. doi:10.4047/jap.2013.5.2.98.

39. Cho SD, Rajitrangson P, Matis BA, Platt JA. Effect of Er,Cr:YSGG laser, air abrasion, and silane application on repaired shear bond strength of composites. Oper Dent. 2013;38(3):E1-9. doi:10.2341/11-054-1.

40. Rizoiu I, Kohanghadosh F, Kimmel AI, Eversole LR. Pulpal thermal responses to an erbium,chromium: YSGG pulsed laser hydrokinetic system. Oral Surg Oral Med Oral Pathol Oral Radiol Endod. 1998;86(2):220-223.

41. Boschian Pest L, Cavalli G, Bertani P, Gagliani M. Adhesive post-endodontic restorations with fiber posts: push-out tests and SEM observations. Dent Mater. 2002;18(8):596602.

42. Bell AM, Lassila LV, Kangasniemi I, Vallittu PK. Bonding of fibre-reinforced composite post to root canal dentin. $J$ Dent. 2005;33(7):533-539. doi:10.1016/j.jdent.2004.11.014.

43. Monticelli F, Toledano M, Tay FR, Sadek FT, Goracci C, Ferrari M. A simple etching technique for improving the retention of fiber posts to resin composites. J Endod. 2006;32(1):44-47. doi:10.1016/j.joen.2005.10.005.

44. Salameh Z, Papacchini F, Ounsi HF, Goracci C, Tashkandi E, Ferrari M. Adhesion between prefabricated fiberreinforced posts and different composite resin cores: a microtensile bond strength evaluation. $J$ Adhes Dent. 2006;8(2):113-117.

45. Xie C, Han Y, Zhao XY, Wang ZY, He HM. Microtensile bond strength of one- and two-step self-etching adhesives on sclerotic dentin: the effects of thermocycling. Oper Dent. 2010;35(5):547-555. doi:10.2341/10-025-1.

46. Goracci C, Tavares AU, Fabianelli A, et al. The adhesion between fiber posts and root canal walls: comparison between microtensile and push-out bond strength measurements. Eur J Oral Sci. 2004;112(4):353-361. doi:10.1111/j.1600-0722.2004.00146.x.

47. Drummond JL, Sakaguchi RL, Racean DC, Wozny J, Steinberg AD. Testing mode and surface treatment effects on dentin bonding. J Biomed Mater Res. 1996;32(4):533-541. doi:10.1002/(SICI)1097-4636(199612)32:4\&lt;533::AIDJBM6\&gt;3.0.CO;2-S. 